Ultrasonic Time-of-Flight Measurements on Binary U-6Nb Cubes

P. R. Souza

July 1, 2005 
This document was prepared as an account of work sponsored by an agency of the United States Government. Neither the United States Government nor the University of California nor any of their employees, makes any warranty, express or implied, or assumes any legal liability or responsibility for the accuracy, completeness, or usefulness of any information, apparatus, product, or process disclosed, or represents that its use would not infringe privately owned rights. Reference herein to any specific commercial product, process, or service by trade name, trademark, manufacturer, or otherwise, does not necessarily constitute or imply its endorsement, recommendation, or favoring by the United States Government or the University of California. The views and opinions of authors expressed herein do not necessarily state or reflect those of the United States Government or the University of California, and shall not be used for advertising or product endorsement purposes.

This work was performed under the auspices of the U.S. Department of Energy by University of California, Lawrence Livermore National Laboratory under Contract W-7405-Eng-48. 


\title{
Ultrasonic Time-of-Flight Measurements on Binary U-6Nb Cubes
}

\author{
Paul R. Souza
}

\section{Summary}

I performed contact ultrasonic time-of-flight measurements on three binary U-6 wt-\% Nb alloy (U-6Nb) cubes. Using the time-of-flight measurement results, thickness, and density, the Acoustic Velocity, Poisson's Ratio, Shear Modulus, and Modulus of Elasticity are calculated. A detailed data is summarized in the spreadsheets 1-6. The calculated data compares the material properties of each cube before and after a heat treatment (HT).

The time-of-flight measurements were performed using the pulse/echo signal overlap technique discussed in the Review of Ultrasonic Pulse/Echo Signal Overlap Technique section of this report. The measurements were made using both the longitudinal and shear ultrasonic modes and acquired in the $\mathrm{X}, \mathrm{Y}$, and $\mathrm{Z}$ axes of each cube, as represented in Figure 1. Thickness and density measurements on the three cubes were performed by the Manufacturing and Materials Engineering Division, Dimensional Inspection Group.

The HT was performed on all three cubes in the Manufacturing and Materials Engineering Division, Heat Treat Shop. The process consisted of $200^{\circ} \mathrm{C}$ for 2 hours in a vacuum furnace, followed by an argon purge to $25^{\circ} \mathrm{C}$. 


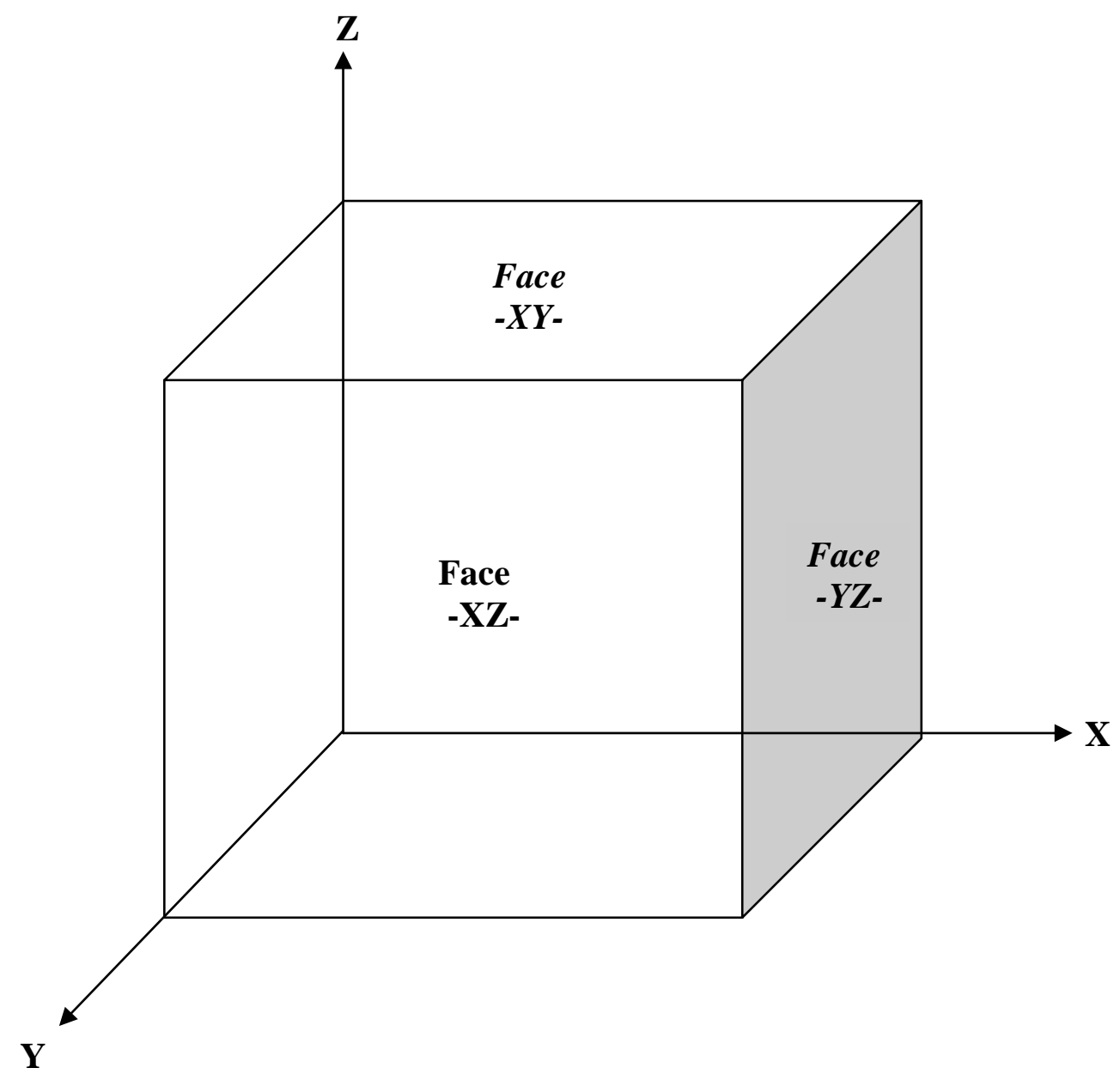

Figure 1: The axes and face designations. The axis orientation of each cube is consistent, tracking the direction the cube was removed from each raw material plate. 


\section{Samples}

To accurately measure the ultrasonic time-of-flight and to calculate the material properties of U-6Nb material, I designed three cubes. The cubes were manufactured by the Manufacturing and Materials Engineering Division, NC Machining Shop. Each cube is manufactured from a different lot of U-6Nb material. The three lots are identified as VIM-VAR-VAR (VVV), VIM-SKULL-VAR (VSV), and Rocky Flats (RF- D84).

Figure 2 shows a portion of the typical plate shape of a raw material lot. The plate measures approximately 2 feet in diameter and was previously used to manufacture component parts. The remnants from the plates were weighed, assigned an identifying descriptor, photographed for accountability, and stored.

I selected three pieces of material, one from each lot and had a cube manufactured from each of the pieces I selected. Two criteria were used in determining my selection. The remnant must have an outside edge from the original plate shape. The edge provides a datum to orient the $\mathrm{X}$-axis of each cube. Also, the remnant had to be large enough to allow for the removal of the cube as far from the datum edge as possible. The mechanical properties near the edge of the remnant may not represent the true mechanical properties of the material. The remnant pieces selected were machined into cubes.

- From the VVV lot, pieceVVV-21 (Figure 3) was machined into cube VVV-21-A.

- From the VSV lot, piece VSV-3 (Figure 4) was machined into cube VSV-3-A.

- From the RF-D84 lot, piece D84-EXCESS (Figure 5) was machined into cube RF-D84-UT.

Figures 3 -5 show the selected remnant material. Each photo indicates the location where the cube was removed from the remnant. To identify the cubes and track their axes, no cube has the same dimensions. The cube dimensions are as follows:

- $\quad$ The VSV-3-A cube has dimensions of X-axis $=31.75 \mathrm{~mm}$ (1.250 inches), Y-axis $=30.48 \mathrm{~mm}$ (1.200 inches), Z-axis = 33.02mm (1.300 inches).

- The VVV-21 cube has dimensions of X-axis $=30.48 \mathrm{~mm}$ (1.200 inches), Y-axis = 29.21mm (1.150 inches), and Z-axis = 31.75mm (1.250 inches).

- $\quad$ The D84-EXCESS cube has dimensions of X-axis $=45.72 \mathrm{~mm}$ (1.800 inches), Yaxis $=46.99 \mathrm{~mm}$ (1.850 inches), and Z-axis $=48.26 \mathrm{~mm}$ (1.900 inches). 


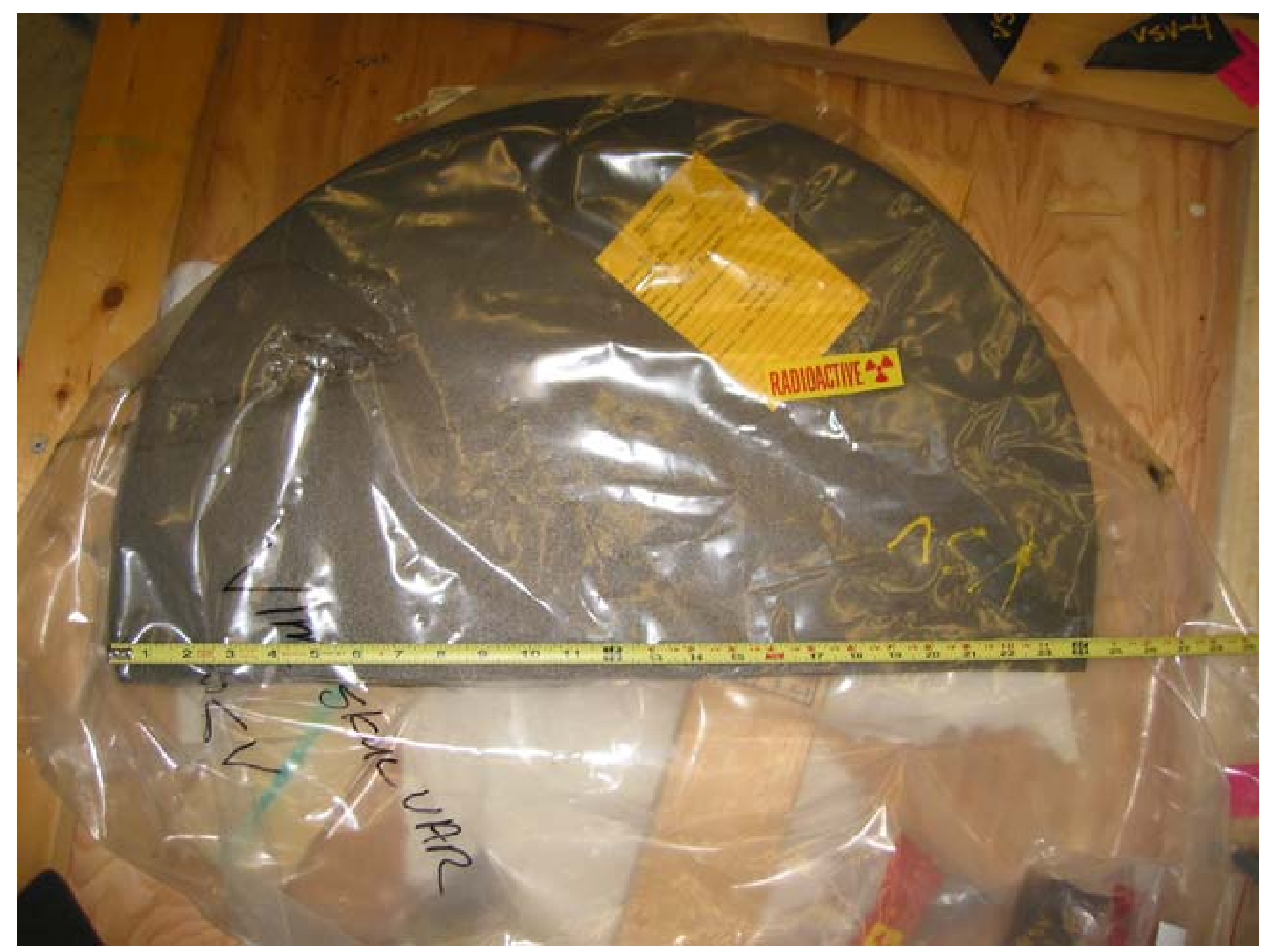

Figure 2: A remnant of the original U-6Nb VSV plate measuring approximately 2 feet in diameter. An outside edge from this lot was used to manufacture a cube. 


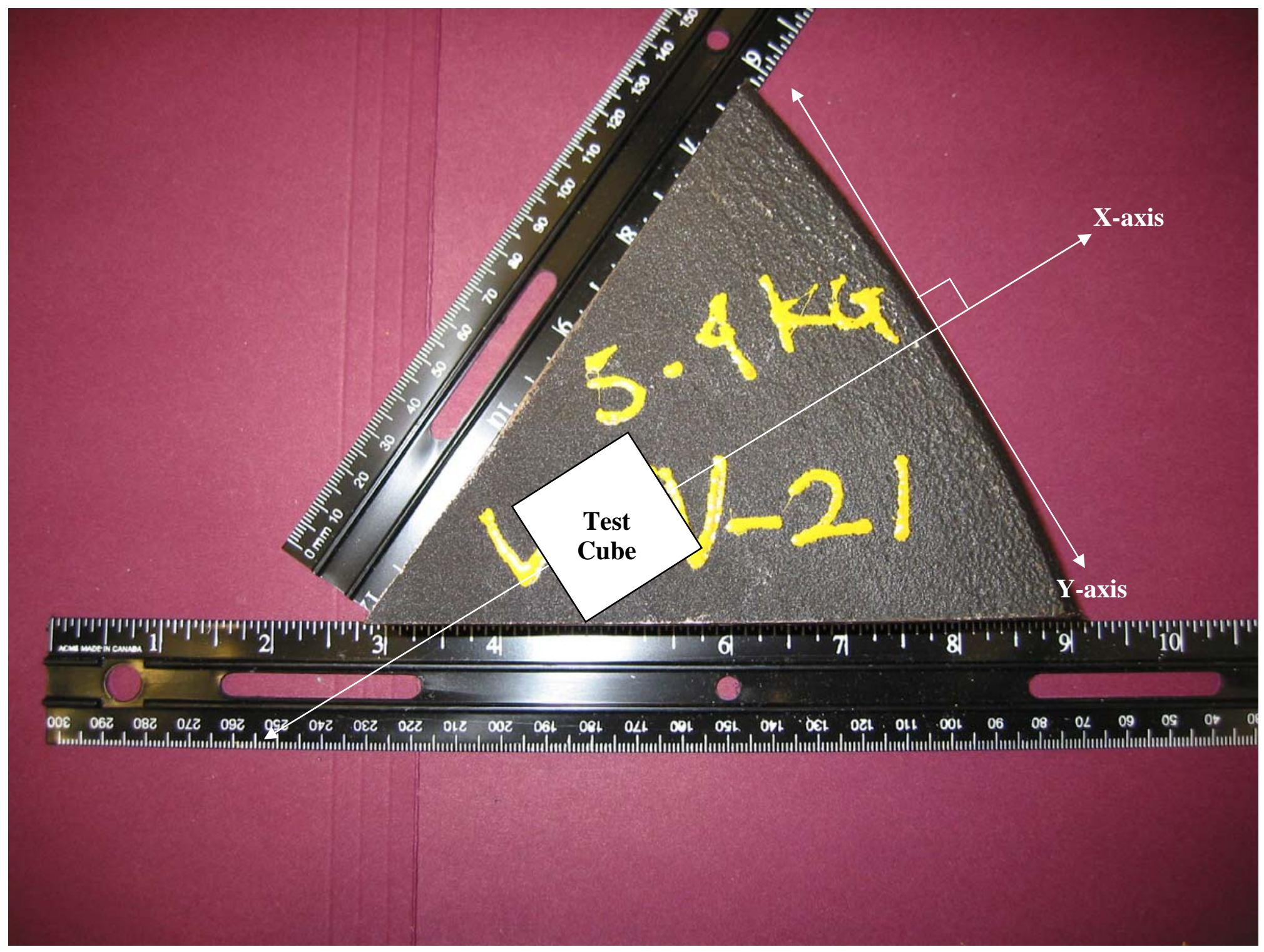

Figure 3: Location where the test cube was made from the VVV-21 remnant. 


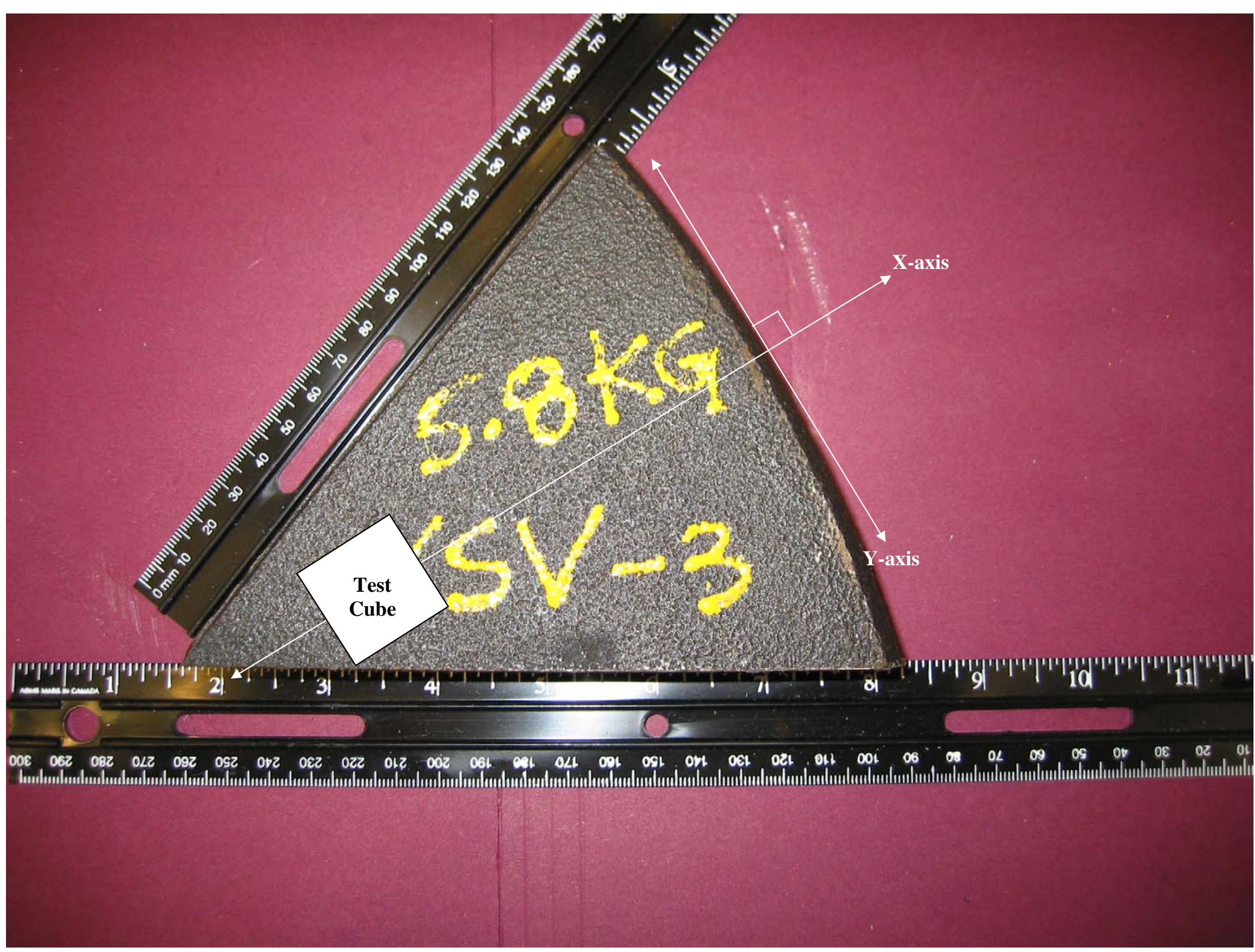

Figure 4: Location where the test cube was made from the VSV-3 remnant. 


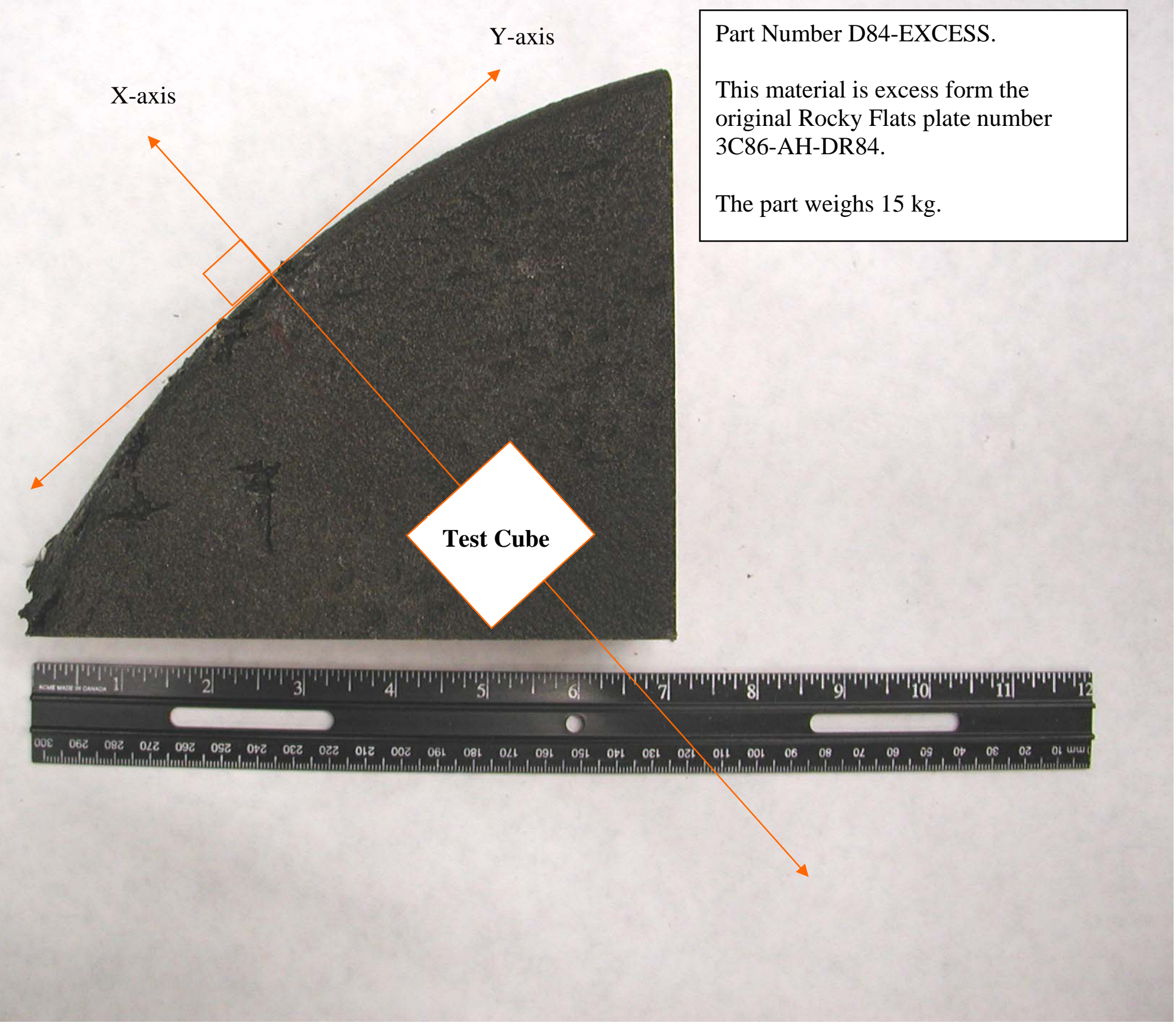

Figure 5: Location where the test cube was made from the D84-EXCESS remnant. 


\section{Ultrasonic Instrumentation}

A Panametrics* model 5800 pulser/receiver is used to transmit and receive the ultrasound, Figure 6. The receiver output of the pulser/receiver is connected to a LeCroy* model 950-wavepro oscilloscope that collects waveforms containing the timeof-flight information. The data from each measurement is digitally stored on a notebook computer connected to the oscilloscope by means of a National Instruments* GPIB (General Purpose Interface Bus) communication port. The computer communicates with the oscilloscope using LeCroy‘s ScopeExplorer software.

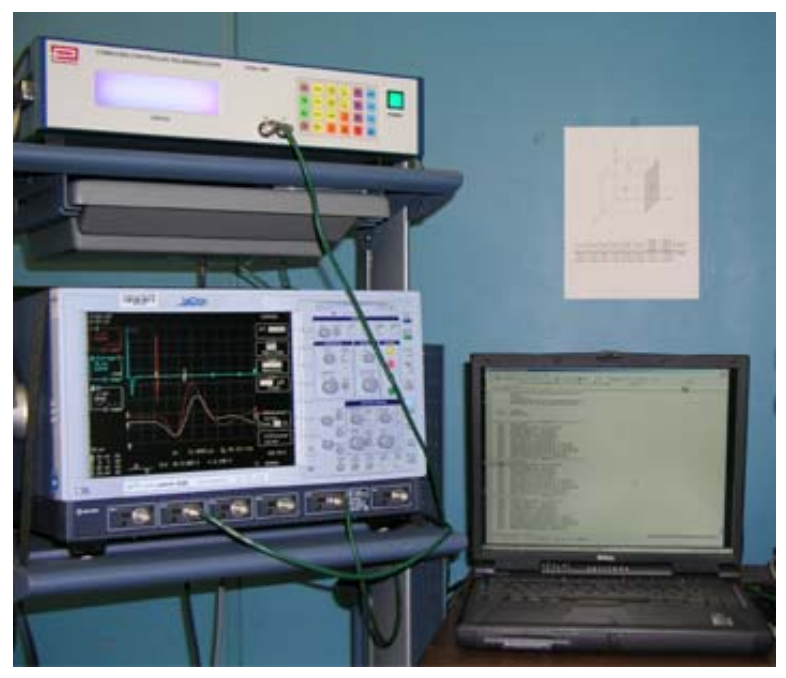

Figure 6: The instrumentation used to make the ultrasonic time-of-flight measurements includes a Panametrics 5800 pulser/receiver, LeCroy 950 wavepro oscilloscope, and a notebook computer.

\section{$\underline{\text { Transducers }}$}

The transducer used to perform the longitudinal ultrasonic measurements is V109VIP-51/2-804 with a dark gray aluminum oxide wear plate. The transducer used to perform the shear ultrasonic measurements is VIP-5-1/2s-686 with a pink aluminum oxide wear plate.

*Panametrics-NDT (A Business of R/D Tech Instruments Inc.) Waltham, MA (800) 225-8330

*LeCroy Corporation, Chestnut Ridge, NY (800) 553-2769

*National Instruments, Austin, TX (888) 280-7645 


\section{The Ultrasonic Pulse/Echo Signal Overlap Technique}

The pulse-echo signal overlap technique was used to measure the ultrasonic time-offlight of U-6Nb cubes. This technique is shown in Figure 7. An initial pulse (IP) excites an ultrasonic transducer which emits sound energy that propagates through the specimen as a wave. The sound energy reflects off the back surface of the specimen and returns to the transducer at time $t_{1}$. Some of this returned sound energy is reflected back into the plate. Again, this energy propagates through the plate and reflects off the back surface and arrives back to the transducer at time $t_{2}$. This continues to occur (e.g. time $t_{3}$ and time $t_{4)}$ until the energy has totally attenuated.

Calculating the material properties from ultrasonic time-of-flight data requires the use of both the longitudinal and shear wave modes. The particle motion of a longitudinal wave is in the same direction as the wave propagation while the particle motion of a shear wave is perpendicular to the wave propagation. At a given frequency in a material, the wavelength and velocity of a shear wave is approximately one/half that of a longitudinal wave. Figure 7a demonstrates these modes. Shear waves are generated using shear wave contact transducers that are polarized. By rotating the shear transducer, anisotropy in a material can be detected through a variation in wave speed.

The overlap measurements are made by placing two time gates, one on each of two consecutive returned back surface reflections, as shown in Figure 7b. The horizontal scaling for these two gates are equal and the position of the gates adjusted so the signals are superimposed on each other. Denoted by arrows, time cursors, one in each time gate, are placed at the beginning and the resultant differential time and frequency are displayed. Differences in the amplitude levels of corresponding reflections indicate the attenuation of the sound as it travels through the specimen. 


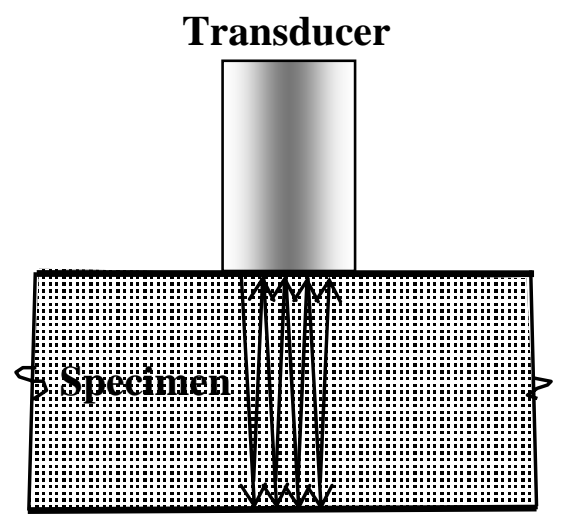

Back Surface
Multiple back surface

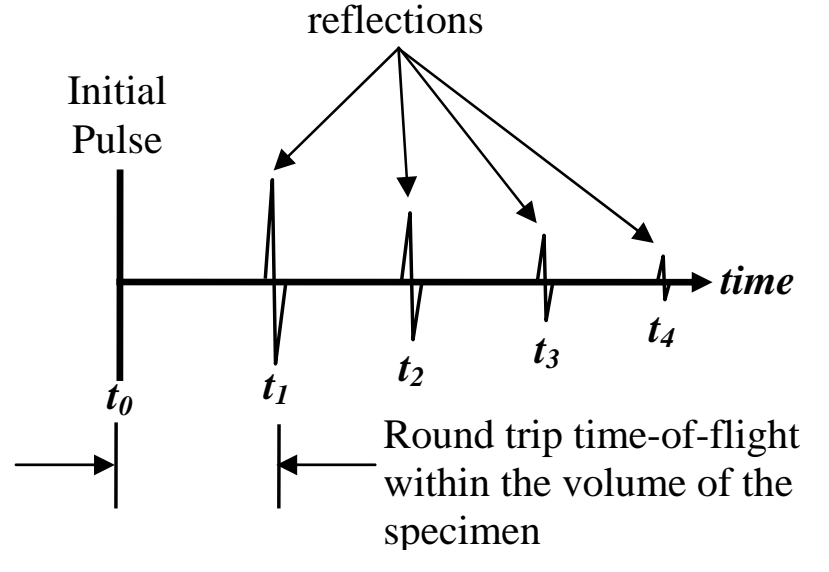

Figure 7 - The time-of-flight measurement between consecutive reflections is used to calculate materials properties. The properties include sound velocity, Poisson's ratio, and both shear and elastic moduli.

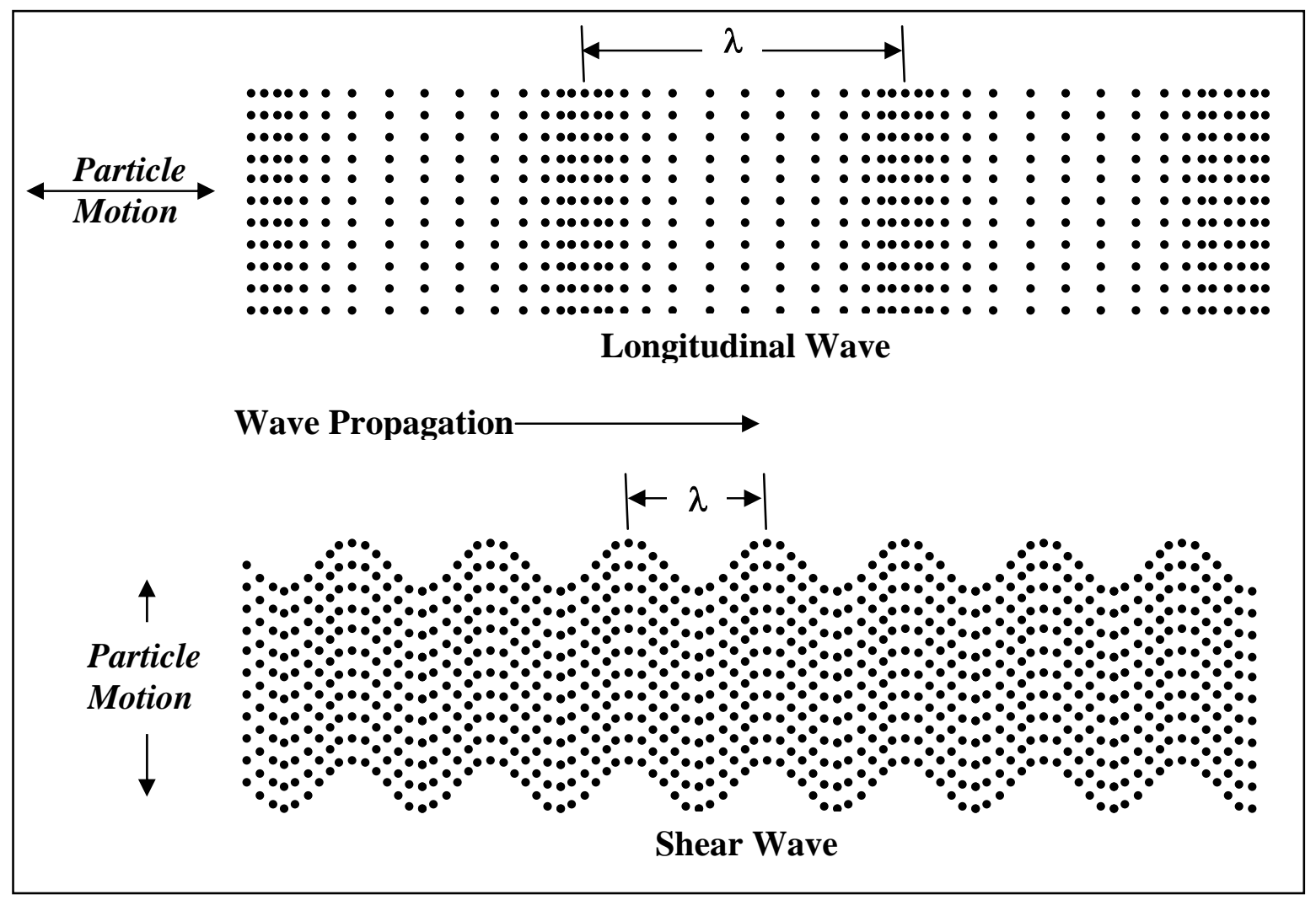

Figure 7a - The particle motion of a longitudinal wave is in the same direction as the wave propagation while the particle motion of a shear wave is perpendicular to the wave propagation. At a given frequency in a material, the wavelength and velocity of a shear wave is approximately one/half that of a longitudinal wave. 


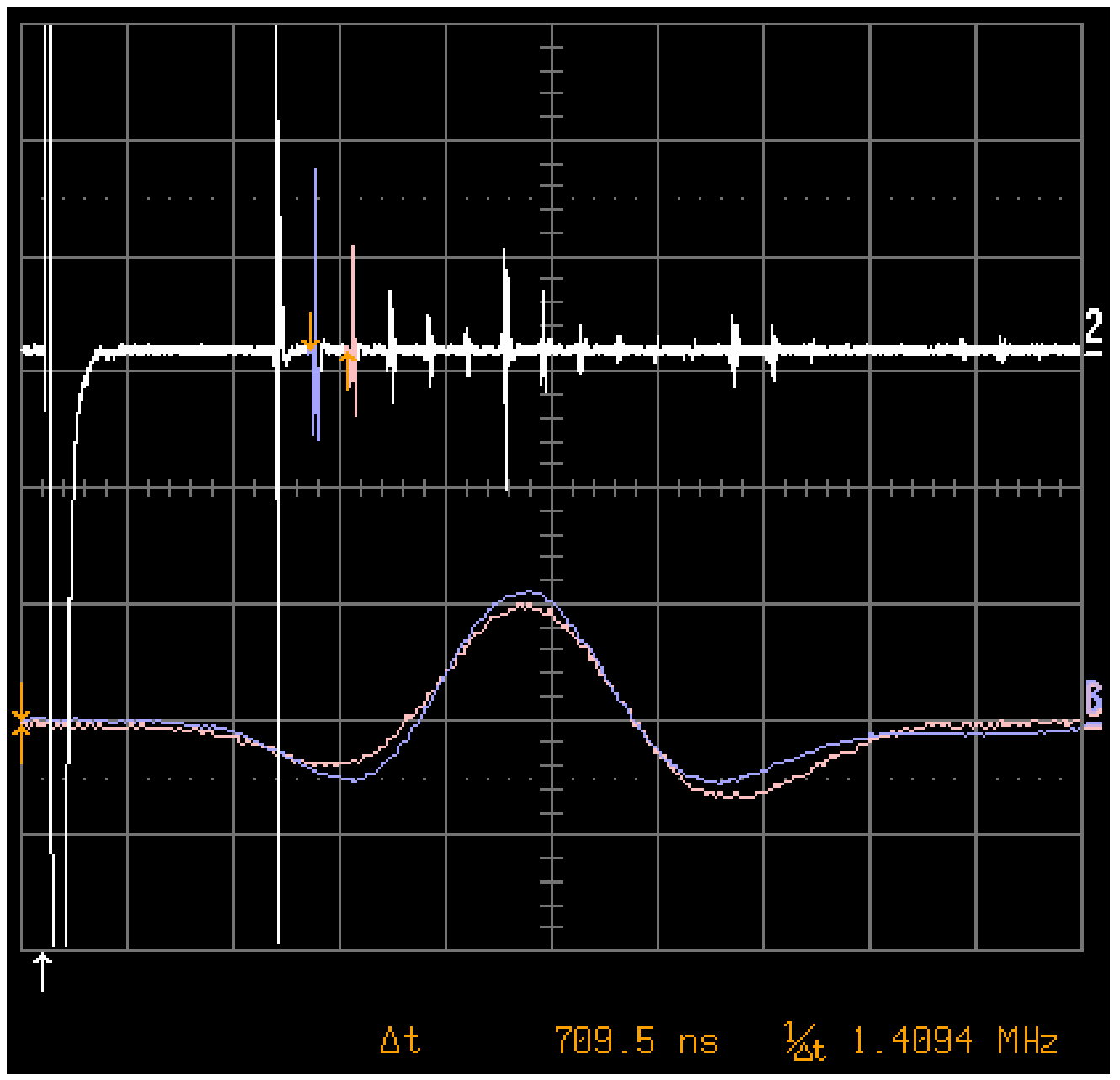

Figure 7b - Snapshot image of an oscilloscope screen showing in the color white the main time trace. In the colors pink and blue, two consecutive back surface reflections are gated out and displayed below the main trace. Horizontally expanded, the gated signals are superimposed on each other. Denoted by arrows, time cursors, one in each gate, are placed at the beginning of the time window and the resultant differential time and frequency are displayed. 


\section{Calculations}

The pulse/echo velocity, $V$, of a material is calculated by

$$
V=2 \frac{T}{t}
$$

where $T=$ material thickness, and $t=$ time-of-flight. The velocity measurement is affected by the density, elastic modulus, parallelism of the front and back surface of the specimen, and specimen thickness.

The Poisson's Ratio, $\mu$, Shear Modulus, $G$, and Elastic Modulus, $E$, are calculated by the equations,

$$
\begin{aligned}
V_{T} & =\sqrt{\frac{G}{\rho}} \\
V_{L} & =\sqrt{\frac{E}{\rho} \frac{1-\mu}{(1+\mu)(1-2 \mu)}}
\end{aligned}
$$

where $V_{T}=$ Transverse Velocity, $V_{L}=$ Longitudinal Velocity, and $\rho=$ Density.

Rearranging terms,

$$
\begin{aligned}
& \mu=\frac{\frac{1}{2}-\left(\frac{V_{T}}{V_{L}}\right)^{2}}{1-\left(\frac{V_{T}}{V_{L}}\right)^{2}} \\
& G=V_{T}^{2} \rho \\
& E=\frac{V_{L}^{2} \rho(1+\mu)(1-2 \mu)}{1-\mu}
\end{aligned}
$$




\section{Data}

Data Spreadsheets 1 - 3 contain data and calculated results before heat-treatment. Data Spreadsheets $4-6$ contain data and results acquired after the heat-treatment. Each data spreadsheet is divided into three sections, one for each of the three faces the transducer contacted when making the ultrasonic time-of-flight measurements. The three faces are identified as face XY, XZ, and YZ (Figure 1). From each face three measurements are made, the longitudinal time-of-flight measurement, and two shear time-of-flight measurements, S1 and S2. To track polarization directionality of the minimum and maximum measured shear wave speed, an illustration accompanies each of the three sections. Figure 8 is an example of this illustration. In addition, the spreadsheets include the density, thicknesses, and calculated material properties.

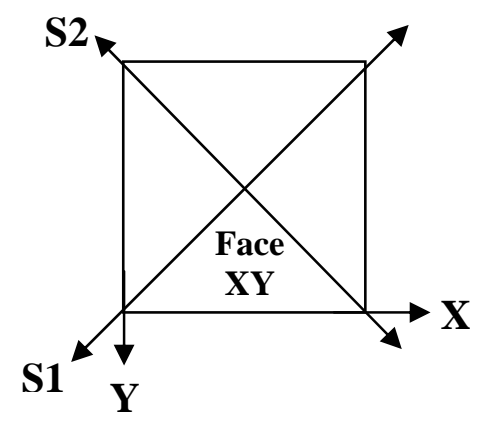

Figure 8: An illustration used to track the directionality of the minimum and maximum shear wave speed. The illustration contains the designation of the cube face which the transducer contacted to make the measurement and the polarization directionality of the minimum and maximum shear wave speed (S1 and S2). In this case the measurement was made on Face XY with the S1 and S2 wave speeds at 45 degrees to the XY axes. One illustration for each of the three measurement directions on each cube is shown in Data Spreadsheets 1 - 6 .

For comparison, I assembled two additional spreadsheets, Comparison Data 1 and Comparison Data 2. The first compares the ultrasonic velocity and mass of each cube before and after heat treatment. Comparison Data 2 compares Poisson's Ratio, the elastic modulus, and the shear modulus of each cube before and after heat treat. The Poisson's 
Ratio, elastic and shear modulus are calculated twice, once using the shear 1 velocity and also using the shear 2 velocity.

\section{Discussion}

The results show the longitudinal velocities increasing in all three axes, on all three cubes, after a heat treatment, although the RF-D84-UT cube changed the least. The shear results show slight anisotropy in all three cubes. The anisotropy between S1 and S2 ranges from $-0.11 \%$ to as great as $3.91 \%$. The negative percentage indicates when the S1 velocity is faster than $\mathrm{S} 2$ velocity. The $\mathrm{X}$-axis (measured on Face $\mathrm{YZ}$ ) in all three cubes has the greatest anisotropy. The RF-D84-UT cube displays the greatest anisotropy but the least amount of change after heat treatment. The RF-D84-UT cube was received in the heat treated condition prior to given another heat treatment, which explains the least amount of change seen in the measurements among the U-6Nb cubes. Before heat treatment, the directionality of the shear polarity S1 and S2 on cubes VVV-21-A and VSV-3-A are at 45 degrees to the cubes axes $\mathrm{X}$ and $\mathrm{Y}$. After heat treatment this

directionality on the VVV-21-A cube realigned itself to be parallel with the $\mathrm{X}$ and $\mathrm{Y}$ axes while the VSV-3-A part did not. 


\section{VVV-21-A \\ Before Heat treatment}

\begin{tabular}{|c|c|c|c|c|}
\hline \multirow[t]{2}{*}{$17490(\mathrm{~kg} / \mathrm{m} 3)$} & \multicolumn{4}{|l|}{ DENSITY } \\
\hline & \multicolumn{4}{|l|}{ Face $-X Y-$} \\
\hline $31.758(\mathrm{~mm})$ & \multicolumn{4}{|l|}{ Thickness (Z direction) } \\
\hline $21.6650(\mu s)$ & \multicolumn{4}{|l|}{ Longitudinal time-of-flight, Face $-\mathrm{XY}-, \mathrm{Z}$ direction } \\
\hline $48.7500(\mu \mathrm{s})$ & \multicolumn{4}{|l|}{ Shear time-of-flight, S1, Face -XY-, $X$ direction $+450 \mathrm{CCW}$} \\
\hline $49.4500(\mu s)$ & \multicolumn{4}{|l|}{ Shear time-of-flight, S2, Face -XY-, 900 from S1 } \\
\hline $2.932(\mathrm{~mm} / \mu \mathrm{s})$ & \multicolumn{4}{|l|}{ Longitudinal velocity, Face -XY-, Z direction } \\
\hline $1.303(\mathrm{~mm} / \mu \mathrm{s})$ & \multicolumn{4}{|l|}{ Shear velocity, S1, Face -XY-, X direction $+450 \mathrm{CCW}$} \\
\hline $1.284(\mathrm{~mm} / \mu \mathrm{s})$ & \multicolumn{4}{|l|}{ Shear velocity, S2, Face -XY-, 900 from S1 } \\
\hline 0.377 & \multicolumn{4}{|l|}{ Poisson's Ratio using Shear velocity S1 } \\
\hline 0.381 & \multicolumn{4}{|l|}{ Poisson's Ratio using Shear velocity S2 } \\
\hline $29.69(\mathrm{GPa})$ & \\
\hline $28.86(\mathrm{GPa})$ & Shear Modulus using Shear velocity S2 & S1 Y & & \\
\hline $81.76(\mathrm{GPa})$ & \multicolumn{4}{|c|}{ Modulus of Elasticity based on Poisson's ratio using Shear Velocity S1 } \\
\hline $79.71(\mathrm{GPa})$ & \multicolumn{4}{|c|}{ Modulus of Elasticity based on Poisson's ratio using Shear Velocity S2 } \\
\hline & \multicolumn{4}{|c|}{ Face -XZ- } \\
\hline $29.205(\mathrm{~mm})$ & \multicolumn{4}{|l|}{ Thickness (Y direction) } \\
\hline $19.6550(\mu \mathrm{s})$ & \multicolumn{4}{|l|}{ Longitudinal time-of-flight, Face -XZ-, Y direction } \\
\hline $45.2500(\mu \mathrm{s})$ & \multicolumn{4}{|l|}{ Shear time-of-flight, S1, Face -XZ-, $X$ direction } \\
\hline $45.3000(\mu s)$ & \multicolumn{4}{|l|}{ Shear time-of-flight, S2, Face -XZ-, 900 from S1 } \\
\hline $2.972(\mathrm{~mm} / \mu \mathrm{s})$ & \multicolumn{4}{|l|}{ Longitudinal velocity, Face -XZ-, Y direction } \\
\hline $1.291(\mathrm{~mm} / \mu \mathrm{s})$ & \multicolumn{4}{|l|}{ Shear velocity, S1, Face -XZ-, X direction } \\
\hline $1.289(\mathrm{~mm} / \mu \mathrm{s})$ & \multicolumn{4}{|l|}{ Shear velocity, S2, Face -XZ-, 900 from S1 } \\
\hline 0.384 & \multicolumn{4}{|l|}{ Poisson's Ratio using Shear velocity S1 } \\
\hline 0.384 & \multicolumn{4}{|l|}{ Poisson's Ratio using Shear velocity S2 } \\
\hline $29.14(\mathrm{GPa})$ & Shear Modulus using Shear velocity S1 & 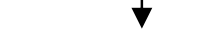 & & \\
\hline $29.08(\mathrm{GPa})$ & Shear Modulus using Shear velocity S2 & $\mathbf{Z}$ & $\downarrow$ & \\
\hline 80.65 (GPa) & Modulus of Elasticity based on Poisson's ratio using S1 & & S2 & \\
\hline 80.49 (GPa) & Modulus of Elasticity based on Poisson's ratio using S2 & & & \\
\hline & Face -YZ- & & & \\
\hline $30.533(\mathrm{~mm})$ & Thickness (X direction) & & & \\
\hline $20.6100(\mu s)$ & Longitudinal time-of-flight, Face - $Y Z-, X$ direction & & $\Delta$ & \\
\hline $47.7000(\mu \mathrm{s})$ & Shear time-of-flight, S1, Face -YZ-, Z direction & & 4 & \\
\hline $47.3500(\mu s)$ & Shear time-of-flight, S2, Face -YZ-, 900 from S1 & & & \\
\hline $2.9629(\mathrm{~mm} / \mu \mathrm{s})$ & Longitudinal velocity, Face $-Y Z-, X$ direction & & & \\
\hline $1.2802(\mathrm{~mm} / \mu \mathrm{s})$ & Shear velocity, S1, Face -YZ-, Z direction & S2 & & \\
\hline $1.2897(\mathrm{~mm} / \mu \mathrm{s})$ & Shear velocity, S2, Face -YZ-, 90o from S1 & & & \\
\hline 0.385 & Poisson's Ratio using Shear velocity S1 & & YZ & \\
\hline 0.383 & Poisson's Ratio using Shear velocity S2 & & & \\
\hline 28.67 (GPa) & Shear Modulus using Shear velocity S1 & $\downarrow$ & & \\
\hline $29.09(\mathrm{GPa})$ & Shear Modulus using Shear velocity S2 & $\mathbf{Z}$ & $\downarrow$ & \\
\hline $79.42(\mathrm{GPa})$ & Modulus of Elasticity based on Poisson's ratio using S1 & & S1 & \\
\hline $80.47(\mathrm{GPa})$ & Modulus of Elasticity based on Poisson's ratio using S2 & & & \\
\hline
\end{tabular}

Data Spreadsheet 1: Density, thickness, acoustic time-of-flight and material property calculations for cube VVV-21-A before heat treatment. 


\section{VSV-3-A \\ Before Heat treatment}

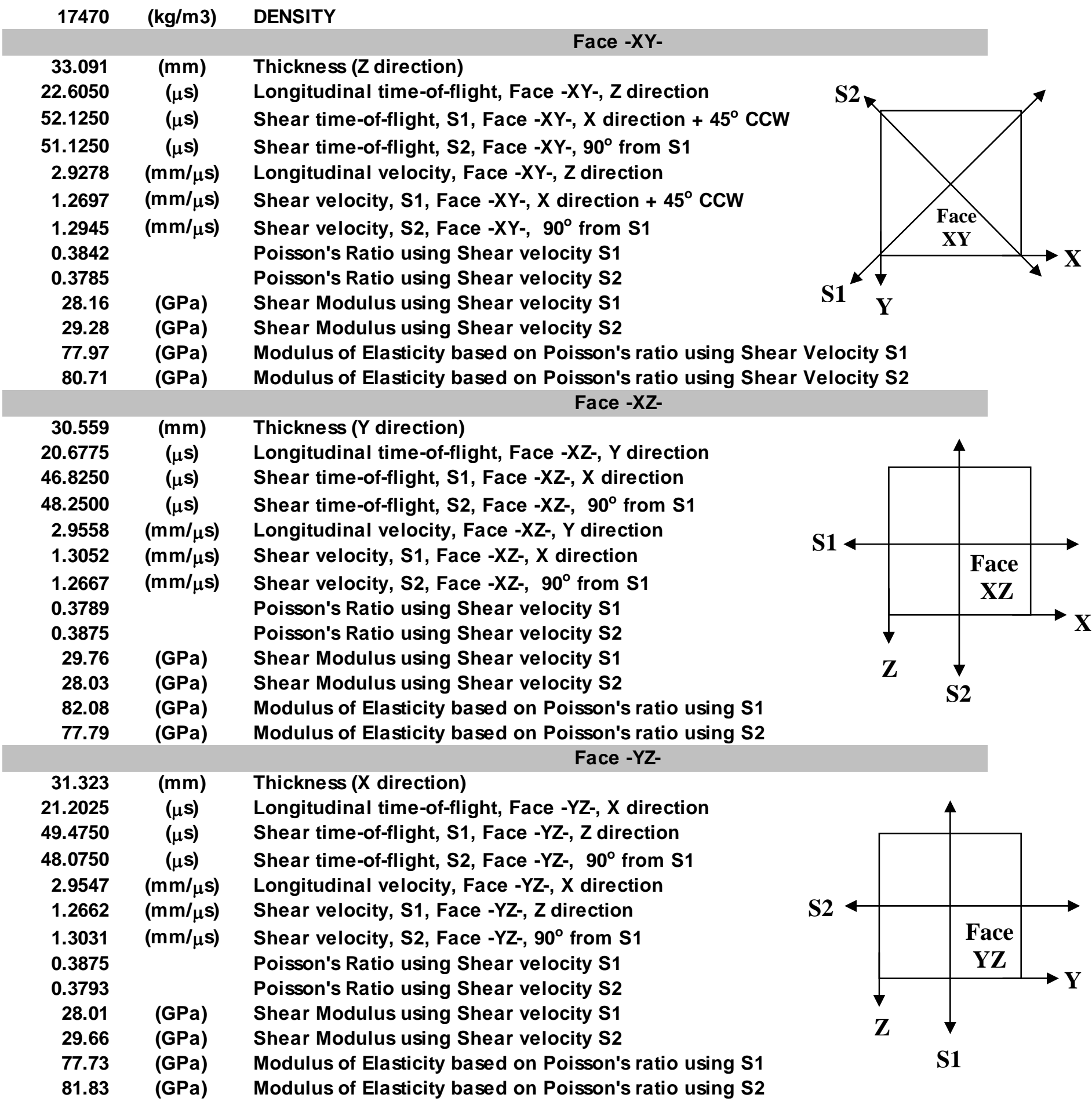

Data Spreadsheet 2: Density, thickness, acoustic time-of-flight, and material property calculations for cube VSV-3-A before heat treatment. 


\section{RF-D84-UT \\ Before Heat treatment}

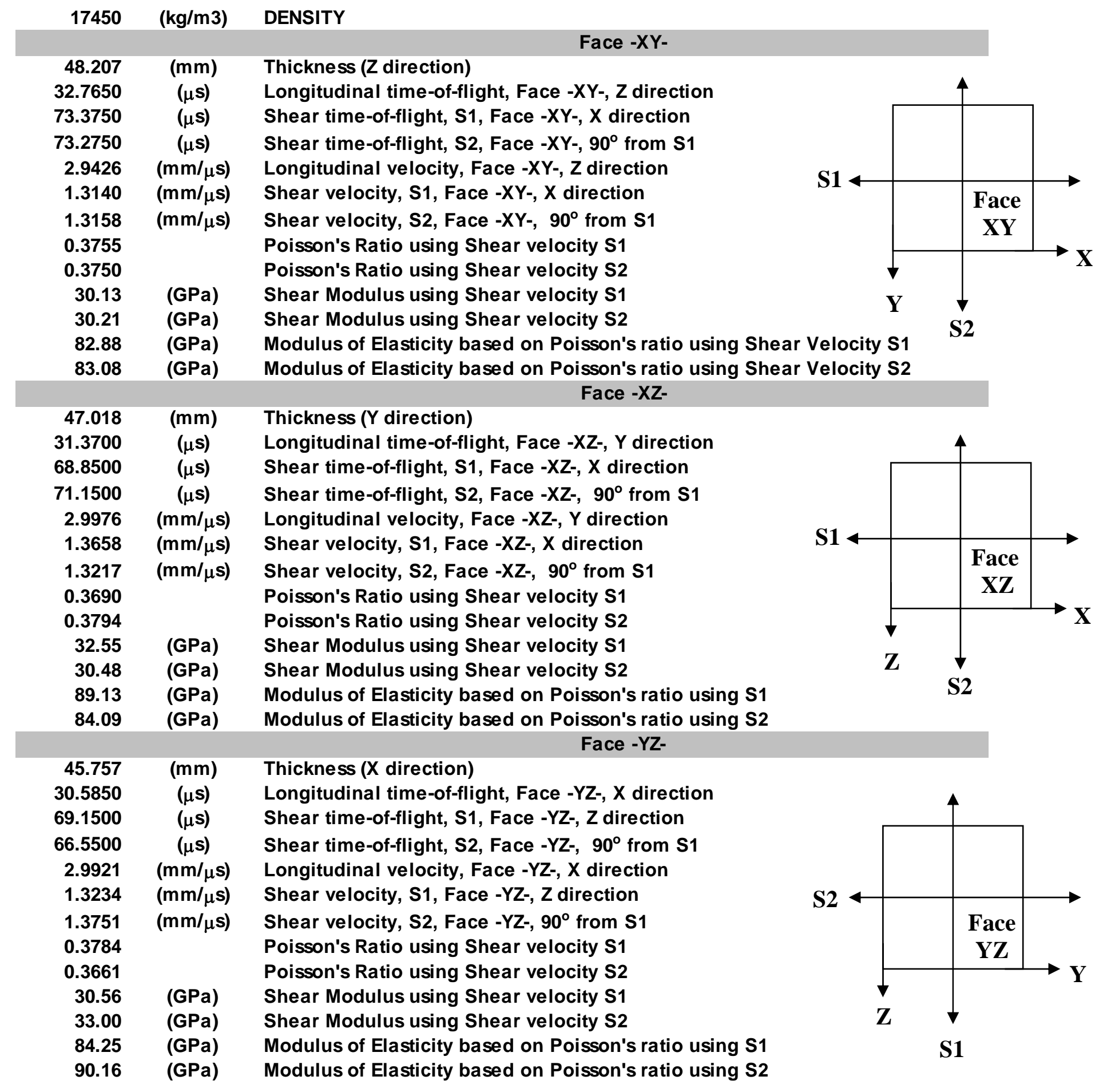

Data Spreadsheet 3: Density, thickness, acoustic time-of-flight, and material property calculations for cube RF-D84-UT before heat treatment. 


\section{VVV-21-A \\ After Heat treatment}

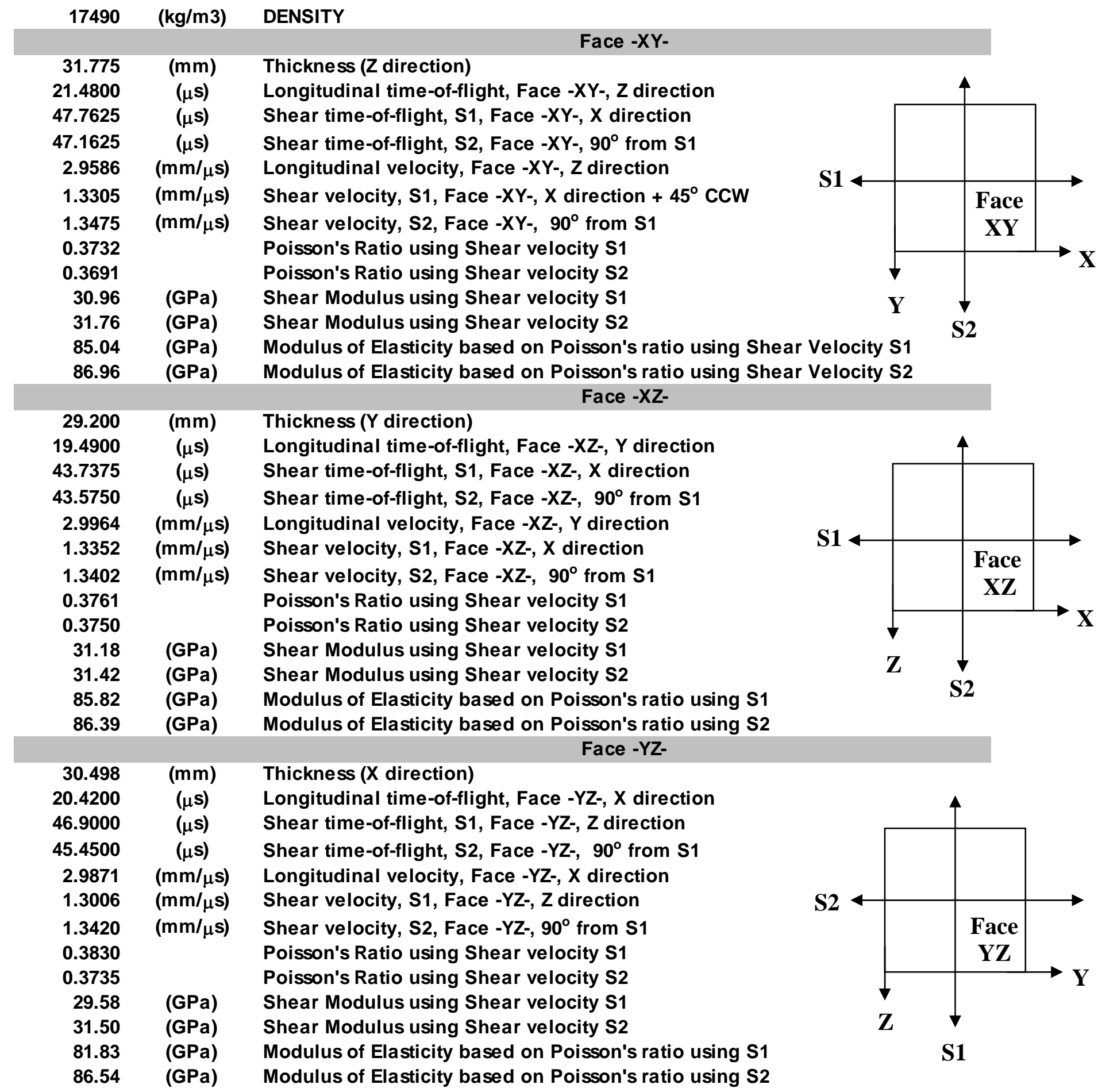

Data Spreadsheet 4: Density, thickness, acoustic time-of-flight, and material property calculations for cube VVV-21-A after heat treatment. 


\section{VSV-3-A \\ After Heat treatment}

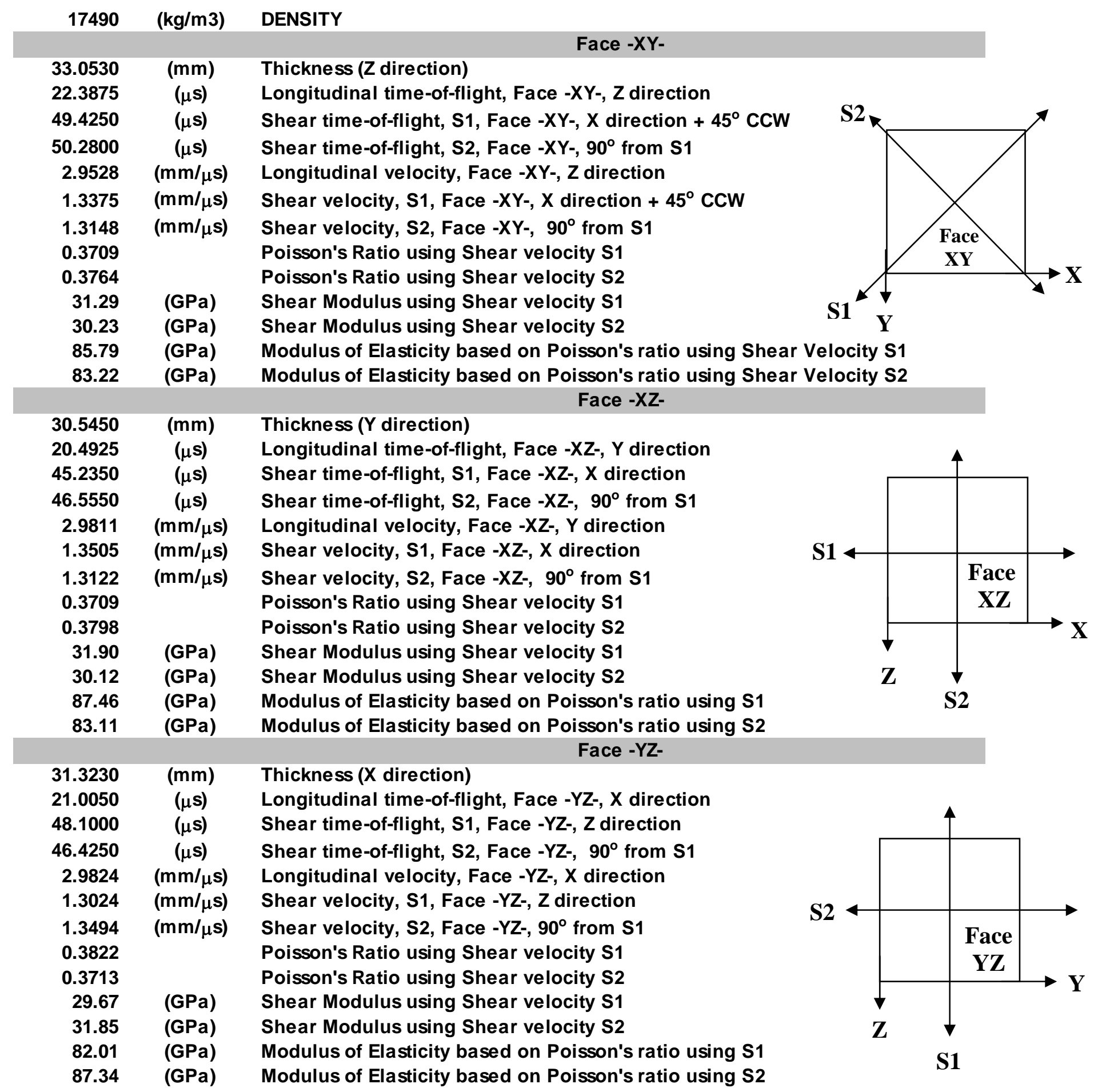

Data Spreadsheet 5: Density, thickness, acoustic time-of-flight, and material property calculations for cube VSV-3-A after heat treatment. 


\section{RF-D84-UT \\ After Heat treatment}

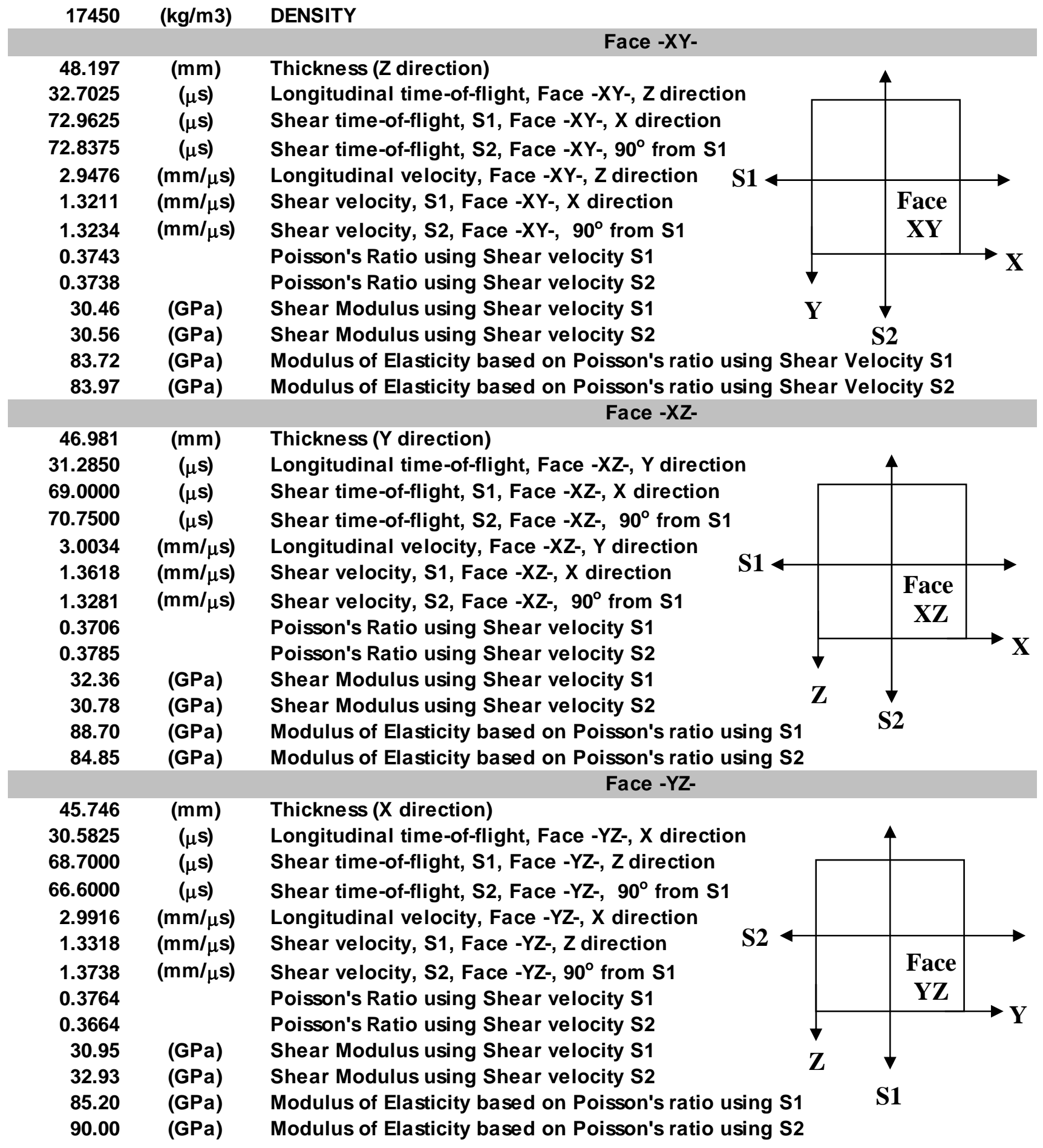

Data Spreadsheet 6: Density, thickness, acoustic time-of-flight, and material property calculations for cube RF-D84-UT after heat treatment. 


\begin{tabular}{|c|c|c|c|c|c|c|c|c|c|}
\hline & & $\begin{array}{c}\text { Before } \\
\text { Heat } \\
\text { Treatment }\end{array}$ & $\begin{array}{l}\text { After Heat } \\
\text { Treatment }\end{array}$ & $\begin{array}{c}\% \text { of Change } \\
\text { After Heat } \\
\text { Treatment }\end{array}$ & \begin{tabular}{|c} 
Average \\
Velocity \\
Before Heat \\
Treatment
\end{tabular} & \begin{tabular}{|} 
Std. Dev. \\
Before \\
Heat \\
Treatment
\end{tabular} & $\begin{array}{c}\text { Average } \\
\text { Velocity } \\
\text { After Heat } \\
\text { Treatment }\end{array}$ & $\begin{array}{l}\text { Std. Dev } \\
\text { After Heat } \\
\text { Treatment }\end{array}$ & $\begin{array}{c}\% \text { of Change } \\
\text { of Average } \\
\text { After Heat } \\
\text { Treatment }\end{array}$ \\
\hline \multicolumn{10}{|c|}{ VVV-21-A } \\
\hline \multirow{6}{*}{$\begin{array}{l}\text { Face } X Y \\
\text { (Z Axis) }\end{array}$} & Density $\left(\mathrm{kg} / \mathrm{m}^{3}\right)$ & 17490 & 17490 & $0.00 \%$ & \multirow{16}{*}{$\begin{array}{l}2.9555 \\
1.2913 \\
1.2878\end{array}$} & \multirow{16}{*}{$\begin{array}{l}0.021 \\
0.011 \\
0.003\end{array}$} & \multirow{16}{*}{$\begin{array}{l}2.9807 \\
1.3221 \\
1.3432\end{array}$} & \multirow{16}{*}{$\begin{array}{l}0.020 \\
0.019 \\
0.004\end{array}$} & \multirow{16}{*}{$\begin{array}{l}0.85 \% \\
2.39 \% \\
4.30 \%\end{array}$} \\
\hline & Longitudinal Velocity $(\mathrm{mm} / \mu \mathrm{s})$ & 2.9317 & 2.9586 & $0.92 \%$ & & & & & \\
\hline & Shear 1 (S1) Velocity $(\mathrm{mm} / \mu \mathrm{s})$ & 1.3029 & 1.3305 & $2.12 \%$ & & & & & \\
\hline & Shear 2 (S2) Velocity $(\mathrm{mm} / \mu \mathrm{s})$ & 1.2844 & 1.3475 & $4.91 \%$ & & & & & \\
\hline & $\%$ of Anisotropy S1 to S2 & $-1.42 \%$ & $1.28 \%$ & $2.70 \%$ & & & & & \\
\hline & Thickness $(\mathrm{mm})$ & 31.7580 & 31.775 & $0.05 \%$ & & & & & \\
\hline \multirow{5}{*}{$\begin{array}{l}\text { Face XZ } \\
\text { (Y Axis) }\end{array}$} & Longitudinal Velocity $(\mathrm{mm} / \mu \mathrm{s})$ & 2.9718 & 2.9964 & $0.83 \%$ & & & & & \\
\hline & Shear 1 (S1) Velocity $(\mathrm{mm} / \mu \mathrm{s})$ & 1.2908 & 1.3352 & $3.44 \%$ & & & & & \\
\hline & Shear 2 (s2) Velocity $(\mathrm{mm} / \mu \mathrm{s})$ & 1.2894 & 1.3402 & $3.94 \%$ & & & & & \\
\hline & $\%$ of Anisotropy S1 to S2 & $-0.11 \%$ & $0.37 \%$ & $0.48 \%$ & & & & & \\
\hline & Thickness $(\mathrm{mm})$ & 29.205 & 29.200 & $-0.02 \%$ & & & & & \\
\hline \multirow{5}{*}{$\begin{array}{l}\text { Face YZ } \\
\text { (X Axis) }\end{array}$} & Longitudinal Velocity $(\mathrm{mm} / \mu \mathrm{s})$ & 2.9629 & 2.9871 & $0.82 \%$ & & & & & \\
\hline & Shear 1 (S1) Velocity $(\mathrm{mm} / \mu \mathrm{s})$ & 1.2802 & 1.3006 & $1.59 \%$ & & & & & \\
\hline & Shear 2 (S2) Velocity $(\mathrm{mm} / \mu \mathrm{s})$ & 1.2897 & 1.3420 & $4.06 \%$ & & & & & \\
\hline & $\%$ of Anisotropy S1 to S2 & $0.74 \%$ & $3.18 \%$ & $2.44 \%$ & & & & & \\
\hline & Thickness $(\mathrm{mm})$ & 30.5330 & 30.498 & $-0.11 \%$ & & & & & \\
\hline \multicolumn{10}{|c|}{ VSV-3-A } \\
\hline \multirow{5}{*}{$\begin{array}{l}\text { Face } X Y \\
\text { (Z Axis) }\end{array}$} & $\begin{array}{r}\text { Density }\left(\mathrm{kg} / \mathrm{m}^{3}\right) \\
\end{array}$ & 17470 & 17490 & $0.11 \%$ & \multirow{15}{*}{$\begin{array}{l}2.9461 \\
1.2804 \\
1.2881\end{array}$} & \multirow{15}{*}{$\begin{array}{l}0.016 \\
0.022 \\
0.019\end{array}$} & \multirow{15}{*}{$\begin{array}{l}2.9721 \\
1.3301 \\
1.3255\end{array}$} & \multirow{15}{*}{$\begin{array}{l}0.017 \\
0.025 \\
0.021\end{array}$} & \multirow{15}{*}{$\begin{array}{l}0.88 \% \\
3.89 \% \\
2.90 \%\end{array}$} \\
\hline & Shear 1 (S1) Velocity (mm/us) & $\begin{array}{l}2.9218 \\
1.2697\end{array}$ & $\begin{array}{l}2.9528 \\
1.3375\end{array}$ & $\begin{array}{l}0.85 \% \\
5.34 \%\end{array}$ & & & & & \\
\hline & Shear 2 (S2) Velocity $(\mathrm{mm} / \mu \mathrm{s})$ & 1.2945 & 1.3148 & $1.57 \%$ & & & & & \\
\hline & $\%$ of Anisotropy S1 to S2 & $1.95 \%$ & $-1.70 \%$ & $3.65 \%$ & & & & & \\
\hline & Thickness $(\mathrm{mm})$ & 33.091 & 33.053 & $-0.11 \%$ & & & & & \\
\hline \multirow{5}{*}{$\begin{array}{l}\text { Face XZ } \\
\text { (Y Axis) }\end{array}$} & Longitudinal Velocity $(\mathrm{mm} / \mu \mathrm{s})$ & 2.9558 & 2.9811 & $0.86 \%$ & & & & & \\
\hline & Shear 1 (S1) Velocity $(\mathrm{mm} / \mu \mathrm{s})$ & 1.3052 & 1.3505 & $3.47 \%$ & & & & & \\
\hline & Shear 2 (S2) Velocity $(\mathrm{mm} / \mu \mathrm{s})$ & 1.2667 & 1.3122 & $3.59 \%$ & & & & & \\
\hline & $\%$ of Anisotropy S1 to S2 & $-2.95 \%$ & $-2.84 \%$ & $0.11 \%$ & & & & & \\
\hline & Thickness (mm) & 30.559 & 30.545 & $-0.05 \%$ & & & & & \\
\hline \multirow{5}{*}{$\begin{array}{l}\text { Face YZ } \\
\text { (X Axis) }\end{array}$} & Longitudinal Velocity $(\mathrm{mm} / \mu \mathrm{s})$ & 2.9547 & 2.9824 & $0.94 \%$ & & & & & \\
\hline & Shear 1 (s1) Velocity $(\mathrm{mm} / \mu \mathrm{s})$ & 1.2662 & 1.3024 & $2.86 \%$ & & & & & \\
\hline & Shear 2 (S2) Velocity $(\mathrm{mm} / \mu \mathrm{s})$ & 1.3031 & 1.3494 & $3.55 \%$ & & & & & \\
\hline & $\%$ of Anisotropy S1 to S2 & $2.91 \%$ & $3.61 \%$ & $0.69 \%$ & & & & & \\
\hline & Thickness $(\mathrm{mm})$ & 31.323 & 31.323 & $0.00 \%$ & & & & & \\
\hline \multicolumn{10}{|c|}{ RF-D84-UT } \\
\hline & Density $\left(\mathrm{kg} / \mathrm{m}^{3}\right)$ & 17450 & 17450 & $0.00 \%$ & & & & & \\
\hline & Longitudinal Velocity $(\mathrm{mm} / \mu \mathrm{s})$ & 2.9426 & 2.9476 & $0.17 \%$ & 2.9774 & 0.030 & 2.9809 & 0.029 & $0.12 \%$ \\
\hline Face $X Y$ & Shear 1 (s1) Velocity $(\mathrm{mm} / \mu \mathrm{s})$ & 1.3140 & 1.3211 & $0.54 \%$ & 1.3344 & 0.028 & 1.3382 & 0.021 & $0.29 \%$ \\
\hline (Z Axis) & Shear 2 (S2) Velocity $(\mathrm{mm} / \mu \mathrm{s})$ & 1.3158 & 1.3234 & $0.58 \%$ & 1.3375 & 0.033 & 1.3418 & 0.028 & $0.32 \%$ \\
\hline & $\%$ of Anisotropy S1 to S2 & $0.14 \%$ & $0.17 \%$ & $0.04 \%$ & & & & & \\
\hline & Thickness (mm) & 48.207 & 48.197 & $-0.02 \%$ & & & & & \\
\hline & Longitudinal Velocity $(\mathrm{mm} / \mu \mathrm{s})$ & 2.9976 & 3.0034 & $0.19 \%$ & & & & & \\
\hline Face $X Z$ & Shear 1 (s1) Velocity $(\mathrm{mm} / \mu \mathrm{s})$ & 1.3658 & 1.3618 & $-0.29 \%$ & & & & & \\
\hline (Y Axis) & Shear 2 (S2) Velocity $(\mathrm{mm} / \mu \mathrm{s})$ & 1.3217 & 1.3281 & $0.48 \%$ & & & & & \\
\hline & $\%$ of Anisotropy S1 to S2 & $-3.23 \%$ & $-2.47 \%$ & $0.75 \%$ & & & & & \\
\hline & Thickness (mm) & 47.018 & 46.981 & $-0.08 \%$ & & & & & \\
\hline & Longitudinal Velocity $(\mathrm{mm} / \mu \mathrm{s})$ & 2.9921 & 2.9916 & $-0.02 \%$ & & & & & \\
\hline Face YZ & Shear 1 (S1) Velocity $(\mathrm{mm} / \mu \mathrm{s})$ & 1.3234 & 1.3318 & $0.63 \%$ & & & & & \\
\hline (X Axis) & Shear 2 (S2) Velocity $(\mathrm{mm} / \mu \mathrm{s})$ & 1.3751 & 1.3738 & $-0.09 \%$ & & & & & \\
\hline & $\%$ of Anisotropy S1 to S2 & $3.91 \%$ & $3.15 \%$ & $0.75 \%$ & & & & & \\
\hline & Thickness $(\mathrm{mm})$ & 45.757 & 45.746 & $-0.02 \%$ & & & & & \\
\hline
\end{tabular}

Comparison Data 1: Comparison of ultrasonic velocity and mass, before and after heat treatment. 


\begin{tabular}{|c|c|c|c|c|c|c|c|c|c|c|}
\hline & & & \begin{tabular}{|c|} 
Before \\
Heat \\
Treatment
\end{tabular} & $\begin{array}{l}\text { After Heat } \\
\text { Treatment }\end{array}$ & $\begin{array}{c}\% \text { of Change } \\
\text { After Heat } \\
\text { Treatment }\end{array}$ & $\begin{array}{c}\text { Average } \\
\text { Before } \\
\text { Heat } \\
\text { Treatment }\end{array}$ & \begin{tabular}{|c} 
Std. Dev. \\
Before \\
Heat \\
Treatment
\end{tabular} & $\begin{array}{c}\text { Average } \\
\text { After Heat } \\
\text { Treatment }\end{array}$ & $\begin{array}{l}\text { Std. Dev. } \\
\text { After Heat } \\
\text { Treatment }\end{array}$ & $\begin{array}{c}\% \text { of Change } \\
\text { of Average } \\
\text { After Heat } \\
\text { Treatment }\end{array}$ \\
\hline & VVV-21-A & & & & & & & & & \\
\hline & Poisson's Ratio S1 & & 0.3769 & 0.3732 & $-0.98 \%$ & 0.3819 & 0.004 & 0.3774 & 0.005 & $-1.18 \%$ \\
\hline & Poisson's Ratio S2 & & 0.3812 & 0.3691 & $-3.17 \%$ & 0.3828 & 0.001 & 0.3725 & 0.003 & $-2.67 \%$ \\
\hline Face XY & Shear Modulus S1 & (GPa) & 29.69 & 30.96 & $4.28 \%$ & 29.17 & 0.51 & 30.57 & 0.87 & $4.82 \%$ \\
\hline (Z Axis) & Shear Modulus S2 & (GPa) & 28.86 & 31.76 & $10.05 \%$ & 29.01 & 0.13 & 31.56 & 0.18 & $8.79 \%$ \\
\hline & Elastic Modulus S1 & (GPa) & 81.76 & 85.04 & $4.01 \%$ & 80.61 & 1.17 & 84.23 & 2.11 & $4.49 \%$ \\
\hline & Elastic Modulus S2 & (GPa) & 79.71 & 86.96 & $9.10 \%$ & 80.22 & 0.44 & 86.63 & 0.30 & $7.99 \%$ \\
\hline & Poisson's Ratio S1 & & 0.3837 & 0.3761 & $-1.98 \%$ & & & & & \\
\hline & Poisson's Ratio S2 & & 0.3840 & 0.3750 & $-2.34 \%$ & & & & & \\
\hline Face XZ & Shear Modulus S1 & (GPa) & 29.14 & 31.18 & $7.00 \%$ & & & & & \\
\hline (Y Axis) & Shear Modulus S2 & (GPa) & 29.08 & 31.42 & $8.05 \%$ & & & & & \\
\hline & Elastic Modulus S1 & (GPa) & 80.65 & 85.82 & $6.41 \%$ & & & & & \\
\hline & Elastic Modulus S2 & (GPa) & 80.49 & 86.39 & $7.33 \%$ & & & & & \\
\hline & Poisson's Ratio S1 & & 0.3852 & 0.3830 & $-0.57 \%$ & & & & & \\
\hline & Poisson's Ratio S2 & & 0.3831 & 0.3735 & $-2.51 \%$ & & & & & \\
\hline Face YZ & Shear Modulus S1 & $(\mathrm{GPa})$ & 28.67 & 29.58 & $3.17 \%$ & & & & & \\
\hline (X Axis) & Shear Modulus S2 & (GPa) & 29.09 & 31.50 & $8.28 \%$ & & & & & \\
\hline & Elastic Modulus S1 & (GPa) & 79.42 & 81.83 & $3.03 \%$ & & & & & \\
\hline & Elastic Modulus S2 & (GPa) & 80.47 & 86.54 & $7.54 \%$ & & & & & \\
\hline & VSV-3-A & & & & & & & & & \\
\hline & Poisson's Ratio S1 & & 0.3842 & 0.3709 & $-3.46 \%$ & 0.3835 & 0.004 & 0.3747 & 0.007 & $-2.31 \%$ \\
\hline & Poisson's Ratio S2 & & 0.3785 & 0.3764 & $-0.55 \%$ & 0.3818 & 0.005 & 0.3758 & 0.004 & $-1.55 \%$ \\
\hline Face $X Y$ & Shear Modulus S1 & (GPa) & 28.16 & 31.29 & $11.12 \%$ & 28.65 & 0.97 & 30.95 & 1.15 & $8.05 \%$ \\
\hline (Z Axis) & Shear Modulus S2 & (GPa) & 29.28 & 30.23 & $3.24 \%$ & 28.99 & 0.85 & 30.73 & 0.97 & $6.01 \%$ \\
\hline & Elastic Modulus S1 & (GPa) & 77.97 & 85.79 & $10.03 \%$ & 79.26 & 2.45 & 85.09 & 2.79 & $7.35 \%$ \\
\hline & Elastic Modulus S2 & (GPa) & 80.71 & 83.22 & $3.11 \%$ & 80.11 & 2.09 & 84.56 & 2.41 & $5.55 \%$ \\
\hline & Poisson's Ratio S1 & & 0.3789 & 0.3709 & $-2.11 \%$ & & & & & \\
\hline & Poisson's Ratio S2 & & 0.3875 & 0.3798 & $-1.99 \%$ & & & & & \\
\hline Face $X Z$ & Shear Modulus S1 & (GPa) & 29.76 & 31.90 & $7.19 \%$ & & & & & \\
\hline (Y Axis) & Shear Modulus S2 & (GPa) & 28.03 & 30.12 & $7.46 \%$ & & & & & \\
\hline & Elastic Modulus S1 & (GPa) & 82.08 & 87.46 & $6.55 \%$ & & & & & \\
\hline & Elastic Modulus S2 & (GPa) & 77.79 & 83.11 & $6.84 \%$ & & & & & \\
\hline & Poisson's Ratio S1 & & 0.3875 & 0.3822 & $-1.37 \%$ & & & & & \\
\hline & Poisson's Ratio S2 & & 0.3793 & 0.3713 & $-2.11 \%$ & & & & & \\
\hline Face YZ & Shear Modulus S1 & (GPa) & 28.02 & 29.67 & $5.89 \%$ & & & & & \\
\hline (X Axis) & Shear Modulus S2 & (GPa) & 29.66 & 31.85 & $7.38 \%$ & & & & & \\
\hline & Elastic Modulus S1 & (GPa) & 77.73 & 82.01 & $5.51 \%$ & & & & & \\
\hline & Elastic Modulus S2 & (GPa) & 81.83 & 87.34 & $6.73 \%$ & & & & & \\
\hline & RF-D84-UT & & & & & & & & & \\
\hline & Poisson's Ratio S1 & & 0.3755 & 0.3743 & $-0.32 \%$ & 0.3743 & 0.005 & 0.3738 & 0.003 & $-0.14 \%$ \\
\hline & Poisson's Ratio S2 & & 0.3750 & 0.3738 & $-0.32 \%$ & 0.3735 & 0.007 & 0.3729 & 0.006 & $-0.16 \%$ \\
\hline Face $X Y$ & Shear Modulus S1 & (GPa) & 30.13 & 32.36 & $7.40 \%$ & 31.08 & 1.29 & 31.89 & 0.81 & $2.61 \%$ \\
\hline (Z Axis) & Shear Modulus S2 & (GPa) & 30.21 & 30.78 & $1.89 \%$ & 31.23 & 1.54 & 31.50 & 1.24 & $0.85 \%$ \\
\hline & Elastic Modulus S1 & (GPa) & 82.88 & 88.70 & $7.02 \%$ & 85.42 & 3.29 & 87.53 & 2.02 & $2.47 \%$ \\
\hline & Elastic Modulus S2 & (GPa) & 83.08 & 84.85 & $2.13 \%$ & 85.78 & 3.83 & 86.57 & 2.97 & $0.92 \%$ \\
\hline & Poisson's Ratio S1 & & 0.3690 & 0.3706 & $0.43 \%$ & & & & & \\
\hline & Poisson's Ratio S2 & & 0.3794 & 0.3785 & $-0.24 \%$ & & & & & \\
\hline Face $X Z$ & Shear Modulus S1 & (GPa) & 32.55 & 32.36 & $-0.58 \%$ & & & & & \\
\hline (Y Axis) & Shear Modulus S2 & (GPa) & 30.48 & 30.78 & $0.98 \%$ & & & & & \\
\hline & Elastic Modulus S1 & (GPa) & 89.13 & 88.70 & $-0.48 \%$ & & & & & \\
\hline & Elastic Modulus S2 & (GPa) & 84.09 & 84.85 & $0.90 \%$ & & & & & \\
\hline & Poisson's Ratio S1 & & 0.3784 & 0.3764 & $-0.53 \%$ & & & & & \\
\hline & Poisson's Ratio S2 & & 0.3661 & 0.3664 & $0.08 \%$ & & & & & \\
\hline Face YZ & Shear Modulus S1 & (GPa) & 30.56 & 30.95 & $1.28 \%$ & & & & & \\
\hline (X Axis) & Shear Modulus S2 & (GPa) & 33.00 & 32.93 & $-0.21 \%$ & & & & & \\
\hline & Elastic Modulus S1 & (GPa) & 84.25 & 85.20 & $1.13 \%$ & & & & & \\
\hline & Elastic Modulus S2 & (GPa) & 90.16 & 90.00 & $-0.18 \%$ & & & & & \\
\hline
\end{tabular}

Comparison Data 2: Comparison of Poisson's Ratio, Elastic Modulus and Shear Modulus before and after heat treatment. 